\title{
Sincronización de Células de Tabaco (Nicotiana tabacum) NT-1
}

\author{
León F. Ruiz, Ana E. Higareda y Marco A. Pardo* \\ Universidad Michoacana de San Nicolás de Hidalgo, Instituto de Investigaciones Químico \\ Biológicas, Edificio B-3, Ciudad Universitaria, Morelia, Michoacán-México \\ (e-mail: mapardo@umich.mx)
}

*autor a quien debe ser dirigida la correspondencia

\section{Resumen}

Se ha evaluado la capacidad sincronizante de afidicolina e hidroxiurea en cultivos de células de tabaco (Nicotiana tabacum) NT-1. Los cultivos sincronizados son poderosas herramientas en estudios moleculares y bioquímicos relacionados al ciclo celular y comúnmente se utilizan químicos para bloquear el ciclo celular. La línea celular de tabaco (Nicotiana tabacum) NT-1 proviene de la línea celular TBY-2, caracterizándose NT-1 por su menor velocidad de crecimiento y tamaño celular heterogéneo. Los resultados mostraron una sincronía del $30 \%$ de NT-1 con afidicolina $5 \mu \mathrm{g} / \mathrm{ml}$ similar a la obtenida con TBY-2. Se probaron diferentes concentraciones de hidroxiurea, obteniéndose niveles óptimos de sincronización de hasta $31 \%$ con $0.75 \mathrm{mM}$. Se muestra también que es posible sincronizar cultivos NT-1 en porcentajes similares a cultivos TBY-2 con afidicolina e hidroxiurea. Para este propósito, se recomienda la hidroxiurea por ser químicamente más estable y económica.

Palabras clave: ciclo celular, sincronización, Nicotiana tabacum, hidroxiurea, afidicolina

\section{Synchronization of tobacco cells (Nicotiana tabacum) NT-1}

\begin{abstract}
The synchronizing capacity of aphidicolin and hydroxyurea on NT-1 cultures of tobacco cells (Nicotiana tabacum) NT-1. Synchronized cell cultures are a powerful tool in biochemistry and molecular studies related to cell cycle and commonly chemicals are used to block the biochemical cycle. The tobacco cell line NT-1 comes from cell line TBY-2, the former being characterized with a slower growth rate and heterogeneous cell size. Results show $30 \%$ synchrony with $5 \mu \mathrm{g} / \mathrm{ml}$ aphidicolin, similar to that obtained with TBY-2. Different concentrations of hydroxyurea were tested, obtaining an optimal synchrony of $31 \%$ at $0.75 \mathrm{mM}$ of concentration. It is also shown that it is possible to synchronize NT-1 cultures in similar percentages to those obtained with TBY-2, with either aphidicolin or hydroxyurea. For this purpose, hydroxyurea is recommended because of its lower cost and chemical stability.
\end{abstract}

Keywords: cell cycle, synchronization, Nicotiana tabacum, aphidicolin, hydroxyurea 


\section{INTRODUCCIÓN}

El desarrollo de las plantas involucra un control estrecho y coordinado de la actividad proliferativa y la diferenciación de tejidos. Para entender la regulación de los procesos de crecimiento de las plantas es necesario identificar los reguladores del ciclo celular vegetal (Beemster et al., 2005; Inzé, 2003). El ciclo celular es el periodo que transcurre de una división a la siguiente. Cada célula es el producto de un ciclo celular, el cual comprende la secuencia ordenada de los procesos $G_{1}-S-G_{2}-M$, donde una célula vegetal duplica sus cromosomas y se divide en dos células. Durante la fase $\mathrm{G}_{1}$ se sintetiza la biomasa requerida para sustentar dos células; en la fase $S$ o de síntesis se produce la replicación del $A D N$, además de algunas proteínas específicas al proceso como las histonas; en la fase $G_{2}$ se sintetizan compuestos necesarios para la mitosis. Y finalmente durante la fase $\mathrm{M}$ o mitótica se lleva a cabo la división física de la célula en dos células hijas idénticas (Singh, 2002).

El conocimiento que se tiene de los procesos citológicos y moleculares del ciclo celular en plantas se debe en parte al desarrollo de técnicas de sincronización. La sincronización consiste en el bloqueo y posterior liberación de células en una fase específica del ciclo celular. Un modelo útil para un análisis detallado de los aspectos moleculares de la división celular son los cultivos de células vegetales en suspensión sincronizados. En estos sistemas la división celular está separada de cualquier contexto del desarrollo; así, en un cultivo sincronizado ideal, todas las células avanzan a través del ciclo celular a la misma velocidad a partir del mismo punto de inicio (Nagata, 2004; Planchais et al., 2000; Sharma, 1999). En un cultivo celular real se dan situaciones en las que no todas las células van a la misma velocidad de crecimiento, y aunque la sincronización se haga correctamente y las células hayan partido de la misma fase, existen condiciones intrínsecas que alteran dicha velocidad como son la masa celular, la energía disponible, el estrés, etc., que alteran la eficiencia de sincronización.

Los reactivos químicos que bloquean el ciclo celular vegetal actúan sobre la maquinaría estructural como el huso mitótico, o la bioquímica, como por ejemplo las enzimas involucradas en la síntesis de ADN (Planchais et al., 2000). Entre los bloqueadores específicos de la fase $\mathrm{S}$ para sincronizar cultivos celulares vegetales se encuentran la hidroxiurea y la afidicolina. La hidroxiurea inhibe la actividad de la ribonucleótido reductasa (RNR), bloqueando el ciclo celular en fase $\mathrm{S}$ temprana, destruyendo de manera específica el radical tirosilo de R2 que secuestra a los iones $\mathrm{Fe}^{3+}$ (Fontecave, 1998). La afidicolina es una molécula extraída del hongo Cephalosporium aphidicola, que inhibe la actividad de la ADN polimerasa alfa y delta al competir con los dCTPs (trifosfatos de desoxicitidina) por el sitio de unión a la enzima (Oguro et al., 1979; Nagata et al., 1992).

Los cultivos en suspensión de células del género Nicotiana han sido ampliamente utilizados en la investigación de la biología celular vegetal. La línea celular de tabaco BY-2 (también llamada TBY-2) fue establecida durante la década de 1960 a partir de plántulas de Nicotiana tabacum L. cv. Bright Yellow 2, en las instalaciones del "Central Research Institute of the Japan Tobacco and Salt Public Corporation" (actualmente "Tobacco Science Research Laboratory, Japan Tobacco, Inc."). A partir de esta línea, An (1985), estableció la línea celular NT-1. Desde entonces la línea celular NT-1 ha sido mantenida en diversos laboratorios, principalmente en Norte América (Nagata et al., 1992; Nagata y Kumagai, 1999; Geelen e Inzé, 2001; Nagata et al., 2004). Las células de tabaco NT-1 han sido utilizadas en estudios de transformación con vectores binarios por Agrobacterium tumefaciens (An, 1985; An, 1986; Allen et al., 1993; Allen et al., 1996), de localización subcelular de proteínas (Persson et al., 2001) y de producción de proteínas recombinantes (Hellwig et al., 2004).

De acuerdo con Nagata et al. (1992); y Nagata y Kumagai (1999) la línea celular NT-1 es genéticamente igual a las células TBY-2. Los cultivos de células en suspensión de tabaco NT-1 son heterogéneos y menos friables que las células TBY-2 (el término friable se utiliza para describir la capacidad de separación de las células), observándose en los dos tipos celulares: células redondeadas (30 - 50 micrómetros) formando agregados o racimos y células alargadas, de 2 a 5 veces más alargadas en uno de sus ejes, formando cadenas lineales o zarcillos (Álvarez et al., 1994; Nagata y Kumagai, 1999). Las diferencias morfológicas se pueden observar en la figura 1. En condiciones de cultivo similares a las células TBY-2, las células NT-1 alcanzan la fase estacionaria a los 7 - 8 días después del subcultivo, en tanto que las células TBY-2 a los $6-7$ días, con una densidad de $15 \times 10^{6}$ células por ml o un PCV ("packed cell volume") del $40 \%$ ( $\%$ v ) (Álvarez et al., 
1994; Robledo-Paz et al., 2006). Debido a estas características de crecimiento heterogéneo y lento, las células NT-1 no se han utilizado en experimentos de sincronización (Nagata y Kumagai, 1999).

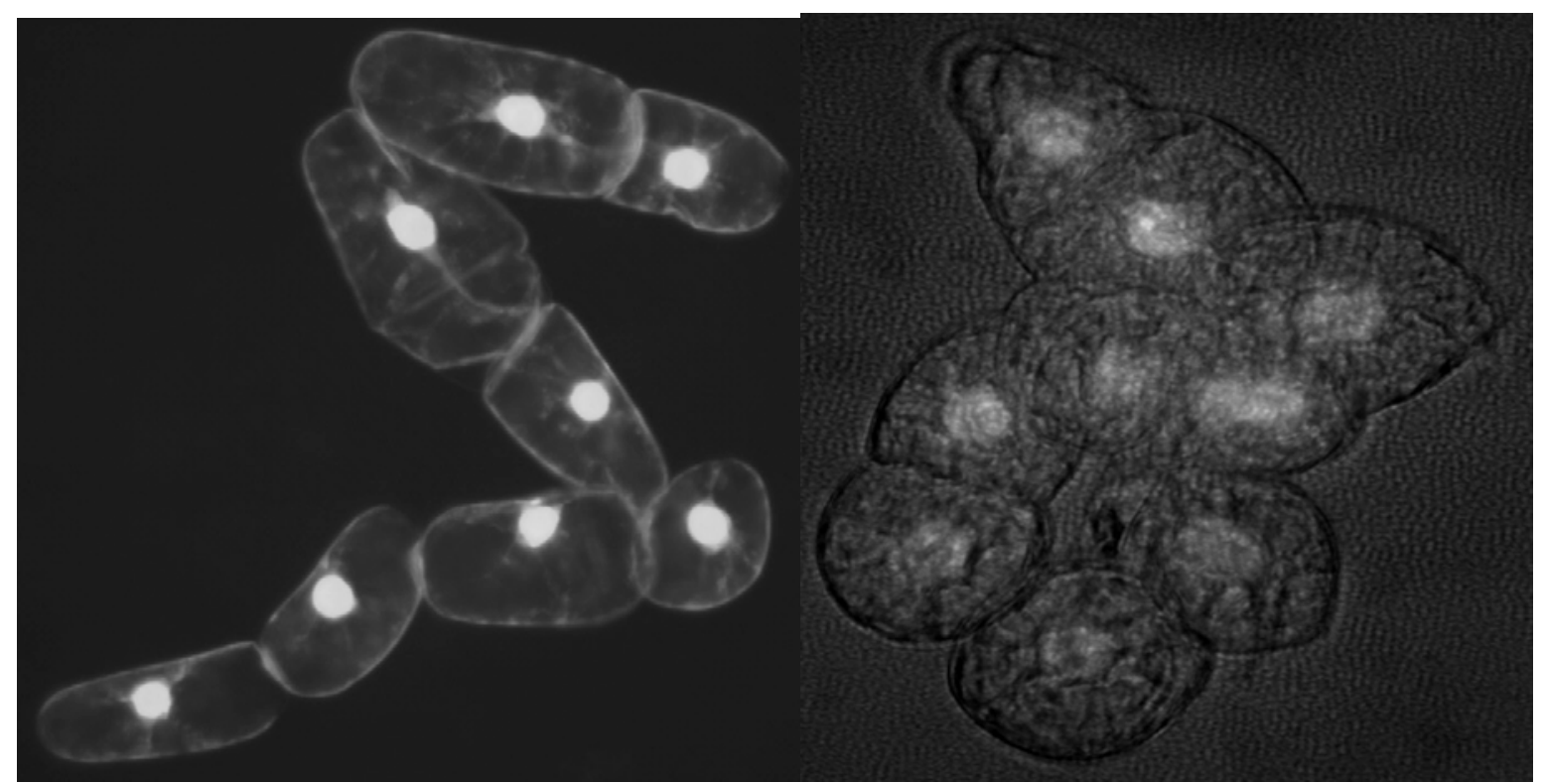

(A) Células de la línea TBY-2

(B) Células de la línea NT-1

Fig. 1: Fotografía de células de cultivos TBY-2 (A) y NT-1 (B) donde se aprecian las diferencias morfológicas y fenotípicas de ambos tipos celulares. El agregado del panel B es frecuente en cultivos NT-1.

En este trabajo se reportan los resultados de sincronización de la línea celular NT-1 añadiendo al cultivo hidroxiurea o afidicolina. Hasta donde se sabe, esta es la primera vez que se reportan experimentos de sincronización exitosos utilizando la línea celular NT-1.

\section{MATERIALES Y MÉTODOS}

\section{Mantenimiento de la línea celular NT-1}

Las células de tabaco NT-1 se mantienen en medio LS (Linsmaier y Skoog, 1964) con las modificaciones descritas por Nagata et al. (1992). Las células se subcultivan cada 7 días (células en fase estacionaria) a medio fresco e incubadas a $28^{\circ} \mathrm{C}$ en oscuridad en un agitador orbital a $120-$ $130 \mathrm{rpm}$. El subcultivo se realiza con una pipeta graduada de $10 \mathrm{ml}$, diámetro de la boca de $2 \mathrm{~mm}$, con filtros de silicón. Se trasfieren $7 \%(\mathrm{v} / \mathrm{v})$ de inóculo a matraces Erlemeyer con rosca de $500 \mathrm{ml}$ con $100 \mathrm{ml}$ de medio LS modificado, en condiciones de esterilidad. La rosca de los matraces se deja parcialmente abierta y el borde es cubierto con cinta porosa (micropore).

\section{Sincronización de células de tabaco NT-1 con afidicolina}

El método de sincronización utilizado fue el establecido para células de tabaco BY-2 por Nagata et al. (1992) con las modificaciones descritas por Samuels et al. (1998). Para iniciar la sincronización, se transfieren $12 \mathrm{ml}$ de un cultivo de tabaco NT-1 de 7 días de crecimiento a un matraz Erlenmeyer de $500 \mathrm{ml}$ con $100 \mathrm{ml}$ de medio LS modificado y $50 \mu \mathrm{l}$ de afidicolina $(10 \mathrm{mg} / \mathrm{ml})$. El cultivo se incuba por 24 horas bajo las condiciones de cultivo estandarizadas.

Para liberar a las células del bloqueo con afidicolina el cultivo se lava con $1000 \mathrm{ml}$ de medio LS modificado incompleto (sin vitaminas ni auxina). El contenido del matraz con afidicolina se vierte sobre el tamiz, permitiendo a la solución drenar a un contenedor en la parte inferior. Las células colectadas en la malla se lavan lentamente con medio LS incompleto, agitando constantemente con una espátula estéril. Después de lavadas, las células son cosechadas en $100 \mathrm{ml}$ de medio LS 
completo. A partir de este momento (tiempo cero) se toman alícuotas de $500 \mu$ l cada hora durante 16 horas para determinar el índice mitótico.

\section{Sincronización de células de tabaco NT-1 por hidroxiurea}

El método de sincronización utilizado es el reportado por Eriksson (1972) y Reichheld (1995). Para iniciar la sincronización, se transfiere con una pipeta estéril (de10 $\mathrm{ml}$ de volumen y abertura de boca $2 \mathrm{~mm}) 12 \mathrm{ml}$ de un cultivo de tabaco NT-1 de 7 días de crecido a un matraz Erlenmeyer de $500 \mathrm{ml}$ con $100 \mathrm{ml}$ de medio LS modificado e hidroxiurea a diferentes concentraciones (5, 2, 1, 0.7500 .5 $\mathrm{mM})$. El cultivo se incuba por 24 horas bajo las condiciones de cultivo estandarizadas.

Para liberar a las células del bloqueo con hidroxiurea el cultivo se lava con $1000 \mathrm{ml}$ de medio LS modificado incompleto (sin vitaminas ni auxina), utilizando un tamiz de nylon estéril con tamaño de malla de $20 \mu \mathrm{m}$. El contenido del matraz con hidroxiurea se vierte sobre el tamiz. Las células colectadas en la malla se lavan lentamente con medio LS incompleto, agitando constantemente con un asa estéril. Después de lavadas, las células se colocan en $100 \mathrm{ml}$ de medio LS completo. A partir de este momento (tiempo cero) se toman alícuotas de $500 \mu \mathrm{l}$ cada hora por 16 horas para la determinación del índice mitótico.

Colecta, fijación y tinción de las células

Las muestras se colectan con puntas recortadas para no destruir las estructuras celulares. Las células colectadas se dejan sedimentar en hielo durante $20 \mathrm{~min}$., se retira el sobrenadante y se resuspenden en un volumen igual al colectado, de solución fijadora que contiene paraformaldehído $(4 \% \mathrm{w} / \mathrm{v})$ y glutaraldehído $(6 \% \mathrm{v} / \mathrm{v})$ disueltos en PBS $1 \mathrm{X}, \mathrm{pH} 7.4$. Las células se almacenan en solución fijadora al menos 12 horas a $4^{\circ} \mathrm{C}$. La solución fijadora conserva la organización morfológica y el contenido químico de la célula en división (Singh, 2002).

Para la determinación del índice mitótico, las células se tiñen con DAPI (4’,6-diamino-2-fenilindol) el cual se prepara como una solución $10 \mathrm{mg} / \mathrm{ml}$ en DMSO (1000X). A las células se les retira la solución fijadora, se les añade $0.5 \mathrm{ml}$ de DAPI $1 \mathrm{X}$ en PBS y se incuban por un mínimo de 6 horas a $4^{\circ} \mathrm{C}$. El índice mitótico se determina por microscopía de epifluorescencia (Microscopio Leica IM50) como el número de células en mitosis dividido por el número total de células contadas y multiplicado por 100 (Singh, 2002). El número total de células contadas por punto de muestreo es de 400 células y cada punto representa el promedio de tres conteos independientes.

\section{RESULTADOS}

\section{Sincronización con afidicolina}

Se quiso conocer los niveles de sincronía de la NT-1 en presencia de afidicolina y compararlos con los obtenidos con la TBY-2 en las mismas condiciones. A una concentración de $5 \mu \mathrm{g} / \mathrm{ml}$, concentración óptima para la línea celular TBY-2, las células NT-1 alcanzan un pico mitótico de aproximadamente $30 \%, 9$ horas después de liberadas del bloqueo (figura 2). Este resultado confirma que la línea NT-1 es sincronizable con afidicolina a niveles similares a los obtenidos con la TBY-2, a pesar de sus diferencias fisiomorfológicas. El nivel de sincronía obtenido para la TBY-2 está dentro de los valores obtenidos por Kumagai-Sano et al. (2006), que van del $30-70 \%$. Estos autores justifican la gran variabilidad en los niveles de sincronía por la sensibilidad del cultivo a varios factores dependientes de las condiciones de crecimiento y manipulación.

\section{Sincronización con hidroxiurea}

La hidroxiurea es un reactivo mucho más económico que la afidicolina, y ha sido ampliamente utilizada en experimentos de sincronización de cultivos celulares vegetales. Con el fin de encontrar una concentración óptima (concentración del reactivo vs. nivel de sincronía) de hidroxiurea, y de acuerdo a la literatura, se decidió iniciar experimentos de sincronización en cultivos de la NT-1, con concentraciones altas previamente descritas como adecuadas para la TBY-2 y otros cultivos, de 60 
mM, 30 mM y 5 mM (Reichheld et al., 1995; Magyar et al., 1993). La figura 3 muestra estos resultados al igual que los de la sincronización con afidicolina de la línea NT-1 de la figura 2, para fines comparativos.

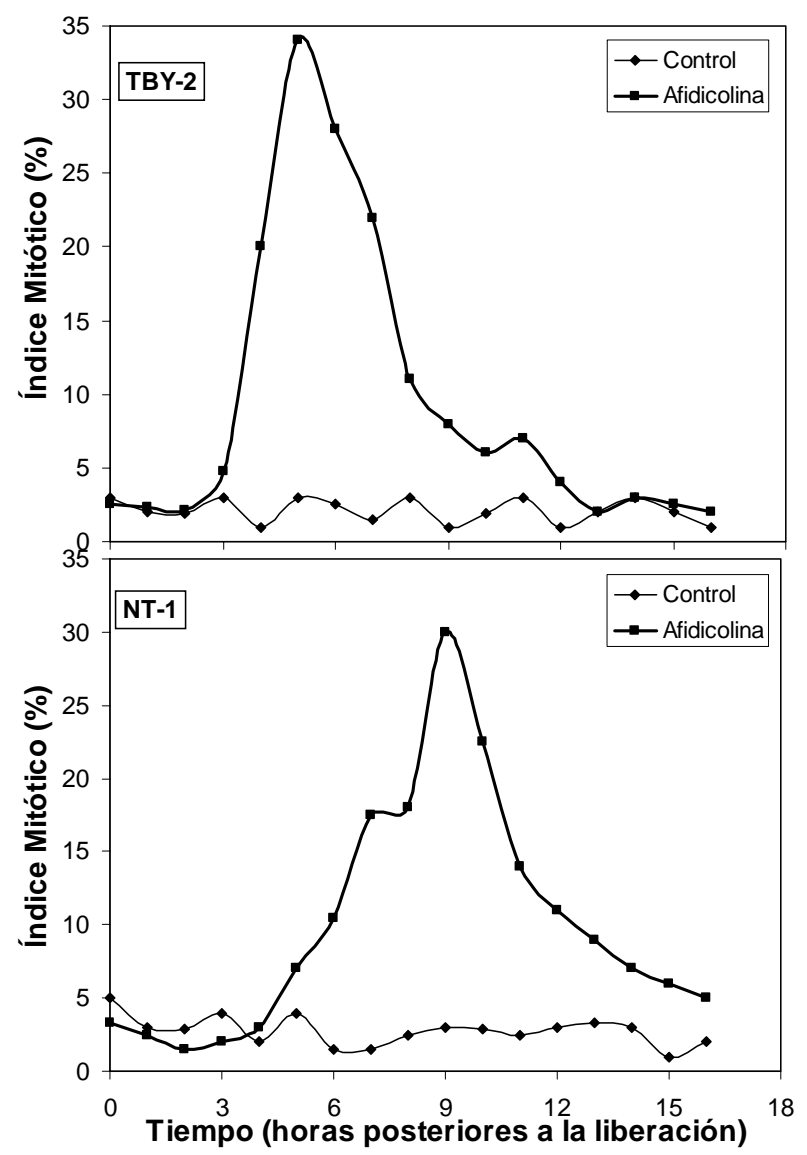

Fig. 2: Nivel de sincronía de las líneas celulares TBY-2 y NT-1 tras su bloqueo con afidicolina. El control fue tratado sólo con agua.

Con la concentración de $60 \mathrm{mM}$ las células jamás se recuperaron del bloqueo y murieron, siendo la única concentración de hidroxiurea en la cual el cultivo no se logró recuperar. A 30 mM y 5 mM los cultivos permanecieron asincrónicos y con una baja actividad mitótica. Estos resultados contrastan con los reportes para las células TBY-2 (Reichheld et al., 1995), donde encuentran que la concentración de hidroxiurea óptima es de 30 mM o 60 mM.

Al comparar las diferentes concentraciones de hidroxiurea utilizadas en otros cultivos de plantas se aprecia que en la mayoría de los casos el intervalo de concentración se encuentra entre $2.5 \mathrm{mM}$ y 10 mM (Conia et al., 1990; Boniotti y Gutierrez, 2001; Pathirana y Eason, 2006). Por lo tanto, se evaluaron estas concentraciones medias de hidroxiurea para sincronizar cultivos de células NT-1, de $2 \mathrm{mM}$ y $1 \mathrm{mM}$ (figura 4).

A estas concentraciones se observa que los cultivos ya presentan sincronía, con un índice de aproximadamente $20 \%$ y $23 \%$ respectivamente, y un pico mitótico a las 12 horas después de liberados. Estos resultados sugerían que la concentración óptima de sincronización con hidroxiurea era cercana a estas concentraciones, por lo que se decidió probar concentraciones más bajas a 1 $\mathrm{mM}$ de hidroxiurea. El resultado de estos experimentos se muestra en la figura 5.

Como se observa, se encontró que una concentración de $0.75 \mathrm{mM}$ es óptima para la línea celular NT-1. A esta concentración se obtuvo un índice mitótico de aproximadamente $31 \%$, similar al obtenido con afidicolina (figura 2). Debido a que existe variabilidad en sincronía de cultivo a cultivo, 
se decidió llevar a cabo un experimento que demostrara la reproducibilidad de los datos obtenidos a la concentración óptima de $0.75 \mathrm{mM}$ de hidroxiurea, cuyos resultados se muestran en la figura 6 . Como se puede observar, aun probando cultivos independientes, se confirman los resultados anteriores con niveles de sincronía reproducibles y confiables.

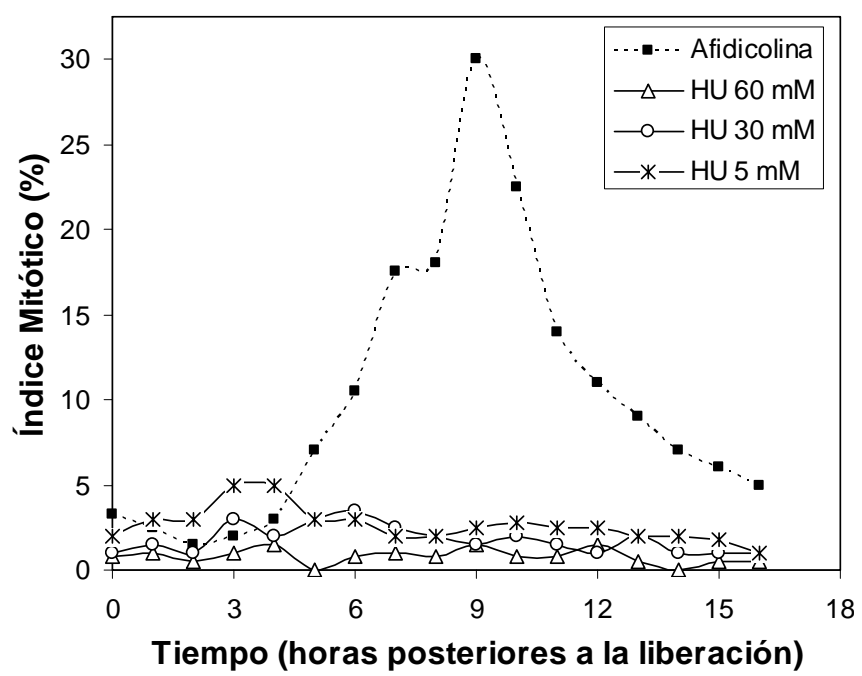

Fig. 3: Nivel de sincronía de la línea celular NT-1 tratada con concentraciones altas de hidroxiurea

(HU). Se muestra, para fines comparativos, la sincronización con afidicolina de la línea NT-1 de la figura 2.

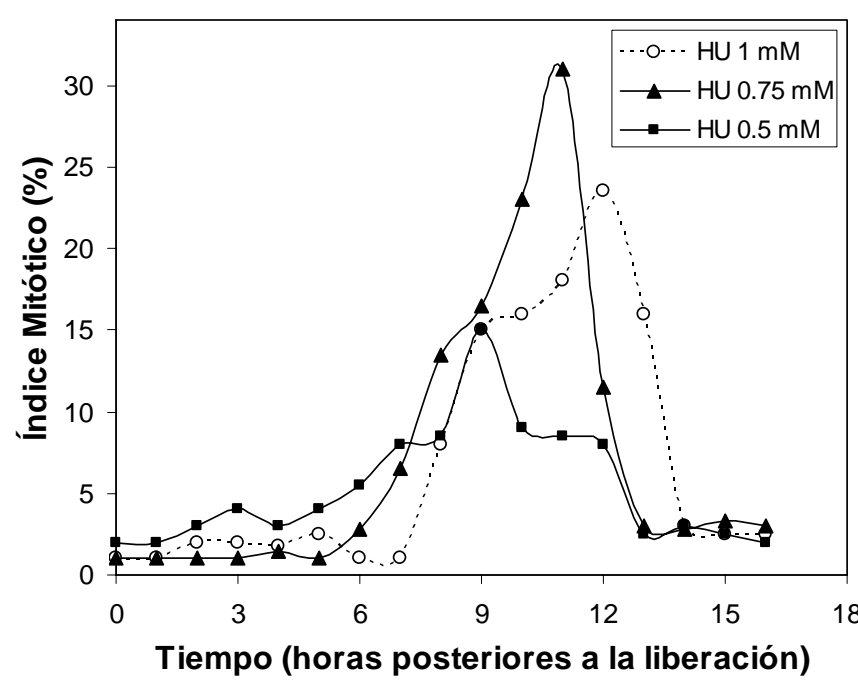

Fig. 5: Nivel de sincronía de la línea celular NT-1 tratada con concentraciones bajas de hidroxiurea $(\mathrm{HU})$.

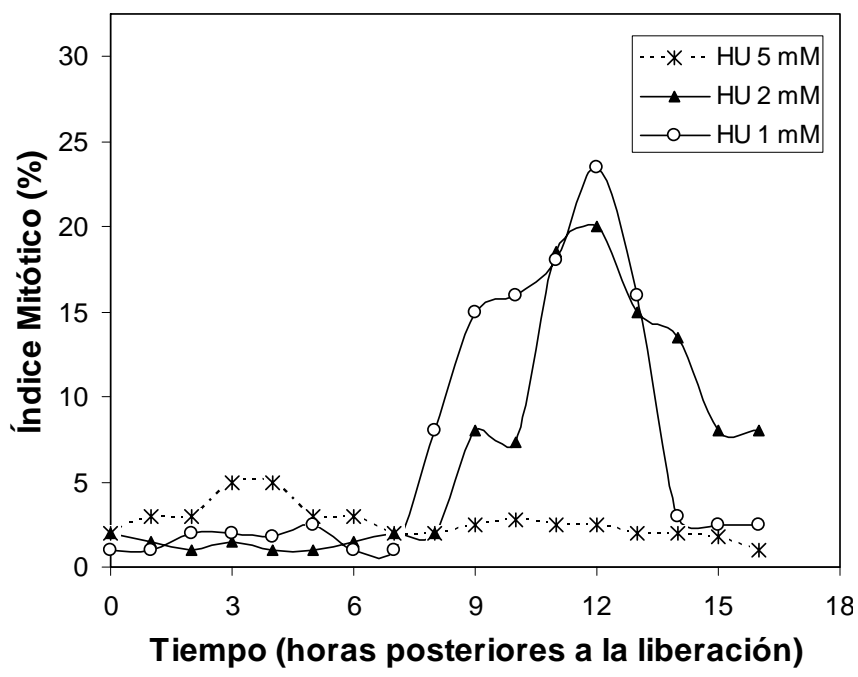

Fig.4: Nivel de sincronía de la línea celular NT-1 tras su bloqueo con concentraciones medias de hidroxiurea $(\mathrm{HU})$.

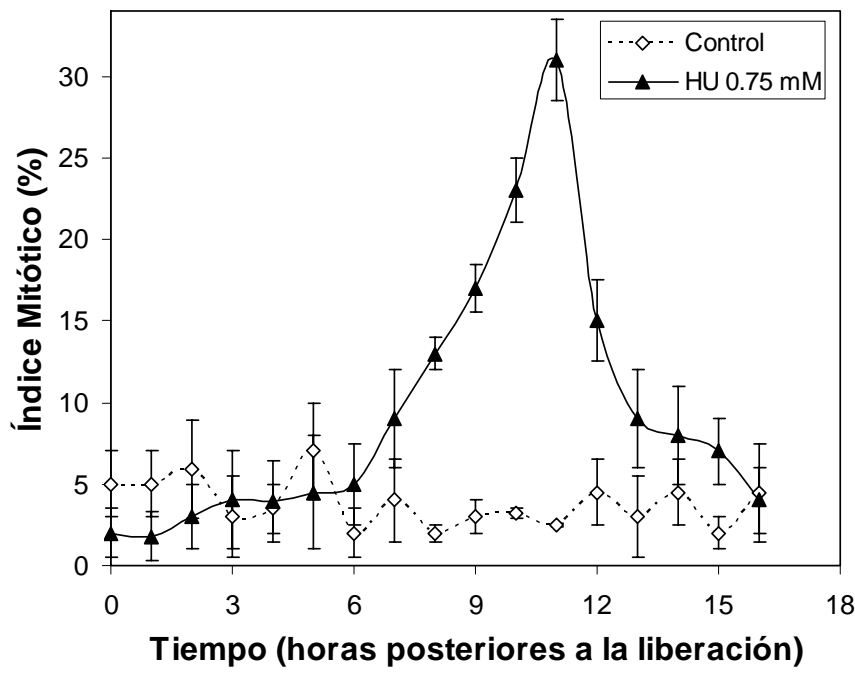

Fig. 6: Reproducibilidad de los niveles de sincronía de cultivos de la línea celular NT-1 tratados con $0.75 \mathrm{mM}$ de $\mathrm{HU}$. El experimento representa un muestreo de tres cultivos independientes.

\section{DISCUSIÓN}

Nagata et al. (1992), reportan un índice mitótico para la línea TBY-2 del $80 \%$ usando $5 \mu \mathrm{g} / \mathrm{ml}$ de afidicolina. Sin embargo, en nuestro laboratorio, y siguiendo las indicaciones del autor, se obtuvo a lo más un $40 \%$ de índice mitótico para esta línea (datos no presentados). En este trabajo se reporta que las células NT-1 alcanzan un pico mitótico de aproximadamente el $31 \%, 9$ horas después de 
liberadas del bloqueo con afidicolina (figura 2). Este porcentaje de sincronía representa un enriquecimiento de aproximadamente 10 veces la cantidad de células en mitosis en comparación con el control asincrónico, y es similar al nivel de sincronía obtenido para la TBY-2 (30 - $40 \%$ ). Las diferencias en sincronía probablemente se deban a las diferencias en la morfología de las células, siendo preferentemente afectadas las células aisladas en lugar de las que forman racimos o cadenas (ver figura 1) (Álvarez et al., 1994).

Al comparar las curvas de sincronización con afidicolina (figura 2) e hidroxiurea (figuras 5 y 6 ) se observa una diferencia temporal en los picos mitóticos, 9 horas con afidicolina y dependiendo de la concentración, hasta 12 horas con hidroxiurea. Una explicación probable es el que a la célula le es más difícil deshacerse de la hidroxiurea que de la afidicolina, lo que es evidente al tratar a los cultivos con distintas concentraciones de hidroxiurea (figura 5 y 6). Esta posibilidad se refuerza por el hecho de que en la concentración más baja $(0.5 \mathrm{mM})$ el pico mitótico coincide con el de afidicolina ( 9 horas). Interesantemente, en experimentos similares con hidroxiurea en cultivos de Haplopappus gracilis se observó un pico mitótico a la hora 12 a concentraciones de 1, 3 y 10 mM (Eriksson, 1972). Por otro lado, la hidroxiurea inhibe la actividad de la ribonucleótido reductasa, enzima requerida para la síntesis de ADN que juega un papel crucial en la regulación de la velocidad de síntesis de ADN, necesario para mantener la relación ADN/masa-celular constante durante la división celular y el proceso de reparación de ADN. Por lo mismo, no sería extraño un mayor efecto genotóxico de la hidroxiurea en comparación con la afidicolina.

Aunque las células TBY-2 y NT-1 tienen el mismo fondo genético (Nagata et al., 1999), son claras las diferencias fenotípicas en los experimentos de sincronización. En cultivos en suspensión las células exhiben cambios metabólicos y morfológicos significativos en respuesta a cambios en el medio extracelular (Singh et al., 1985). Entre los parámetros que pueden afectar el fenotipo celular se encuentran las concentraciones de azúcares, vitaminas, minerales, hormonas, densidad celular, entre otros. Además, pequeños cambios en las condiciones ambientales como temperatura, luz, agitación, volumen del cultivo vs. volumen del matraz, permeabilidad de los gases, $\mathrm{pH}$ del medio, protocolo de esterilización, etc. tienen efectos impredecibles en el crecimiento y fisiología de las células (Renaudin, 2004). Las células NT-1 se han subcultivado por más de 20 años en condiciones subóptimas en comparación con las células TBY-2 (Nagata et al., 1992; Nagata y Kumagai 1999). El término subóptimo se emplea para describir condiciones de cultivo diferentes a las establecidas para las células TBY-2, las cuales modifican la velocidad de crecimiento de las células NT-1. Entre las diferencias documentadas en el mantenimiento de las células NT-1 se encuentran el pH (RobledoPaz et al., 2006), la concentración de $\mathrm{KH}_{2} \mathrm{PO}_{4}$ (Allen et al., 1993, 1996), la temperatura (Persson et al., 2001), la agitación (Allen et al., 1993; Persson et al., 2001; Robledo-Paz et al., 2006) y el fotoperiodo (Álvarez et al., 1994). La diversidad en las condiciones de mantenimiento de la línea celular NT-1 probablemente originó una enorme variabilidad en la población de las células del cultivo, ya sea como resultado de la selección de mutaciones genéticas, cambios epigenéticos o una combinación de procesos (Meins, 1983). Esto explica las diferencias no solo entre las células TBY-2 y NT-1, sino las diferencias observadas entre las mismas células NT-1. Hasta donde se sabe, la línea NT-1 no ha sido utilizada en experimentos de sincronización, simplemente se ha subcultivado sin asegurarse de mantener una elevada velocidad de crecimiento. Por lo tanto, es probable que debido a este mantenimiento subóptimo, las células NT-1 muestren una velocidad de crecimiento menor a las células BY-2, completando su ciclo celular en 16 horas en comparación con el ciclo celular de 13 - 14 horas de las células TBY-2 (datos no presentados). Es importante resaltar que no hay antecedentes documentados acerca de la duración del ciclo celular de las células NT-1.

\section{CONCLUSIONES}

Del presente trabajo se concluye que es posible sincronizar cultivos de la línea NT-1 en porcentajes de sincronía similares a los obtenidos para la línea BY-2 con afidicolina (30 - $40 \%$ de índice mitótico). Asimismo, se concluye que con hidroxiurea se logran niveles de sincronía similares a los obtenidos con afidicolina, con una concentración final óptima de $0.75 \mathrm{mM}$ de HU. Este resultado es relevante para el área también, debido a que la hidroxiurea es mucho más económica y de mayor estabilidad química que la afidicolina. 


\section{AGRADECIMIENTOS}

Los autores agradecen el apoyo de la Coordinación de la Investigación Científica de la UMSNH y al CONACYT.

\section{REFERENCIAS}

Allen, G.C. y otros cinco autores; Scaffold attachment regions increase reporter gene expression in stably transformed plant cells, Plant Cell: 5, 603-613 (1993).

Allen, G.C. y otros seis autores; High-level transgene expression in plant cells: effects of a strong scaffold attachment region from tobacco, Plant Cell: 8, 889-913 (1996).

Álvarez, R.C., S.J. Nissen y S.G. Ernst; Selection, enrichment and initial characterization of an elongated cell culture of tobacco, Plant Sci.: 103. 73-79 (1994).

An, G.; High efficiency transformation of cultured tobacco cells, Plant Physiol.: 79, 568-570 (1985).

An, G.; Development of plant promoter expression vectors and their use for analysis of differential activity of nopaline synthase promoter in transformed tobacco cells, Plant Physiol.: 81, 86-91 (1986).

Beemster, G.T.S., V. Mironov y D. Inzé; Turning the cell-cycle engine for improved plant performance, Curr. Opin. Biotech.: 16, 142-146 (2005).

Boniotti, M.B. y C. Gutierrez: A cell-cycle-regulated kinase activity phosphorylates plant retinoblastoma protein and contains, in Arabidopsis, a CDK/cyclin D complex, Plant J.: 28, 341-350 (2001).

Conia, J. y otros cinco autores; Reversible accumulation of plant suspension cell cultures in $\mathrm{G}_{1}$ phase and subsequent synchronous traverse of the cell cycle, Plant Physiol.: 94, 1568-1574 (1990).

Eriksson, T.R.; Growth and cell division of cultured cells and protoplasts, In Fermentation technology today by G. Terui, vol 890, pp 673 - 676, Proc. IV IFS, Osaka, Japan (1972).

Fontecave, M.; Ribonucleotide reductase and radical reactions, Cell Mol. Life Sci.: 54, 684-695 (1998).

Geelen, D.N.V. y D.G. Inzé; A bright future for the bright yellow-2 cell culture, Plant Physiol.: 127, 1375-1379 (2001).

Hellwig, S., J. Drossard, R.M. Twyman y R. Fischer; Plant cell cultures for production of recombinant proteins, Nat. Biotechnol.: 22, 1415-1422 (2004).

Inzé, D.; Why should we study the plant cell cycle, J. Exp. Bot.: 54, 1125-1126 (2003).

Kumagai-Sano, F., T. Hayashi, T. Sano y S. Hasezawa; Cell cycle synchronization of BY-2 cells, Nat. Protocols: 1, 2621-2627 (2006).

Linsmaier, E.M. y F. Skoog; Organic growth factor requirements of tobacco tissue cultures, Physiol. Plant: 18, 100-127 (1964).

Magyar, Z. y otros cinco autores; Active cdc2 genes and cell cycle phase-specific cdc2-related kinase complexes in hormone-stimulated alfalfa cells, Plant J.: 4, 151-161 (1993).

Meins, F.; Heritable variation in plant cell culture, Annu. Rev. Plant Physiol.: 34, 327-346 (1983). 
Nagata, T. When I encountered tobacco BY-2 cells!, In Tobacco BY-2 cells, Biotechnology in agriculture and forestry by T. Nagata, S. Hasezawa y D. Inzé, vol. 53(347), pp 1-5 Springer-Verlag, Berlin y Heidelberg (2004).

Nagata, T. y F. Kumagai; Plant cell biology through the window of the highly synchronized tobacco BY-2 cell line, Meth. Cell Sci.: 21, 123-127 (1999).

Nagata, T., Y. Nemoto, y S. Hasezawa; Tobacco BY-2 cell line as the HeLa cells in the cell biology of higher plants, Int. Rev. Cytol.: 132, 1-30 (1992).

Nagata, T., K. Sakamoto y T. Shimizu; Tobacco BY-2 cells: the present and beyond, In Vitro Cell Dev. Biol. Plant: 40, 163-166 (2004).

Oguro, M. y otros cuatro autores; The mode of inhibitory action by aphidicolin on eukaryotic DNA polimerase alfa, Eur. J. Biochem.: 97, 603-607 (1979).

Pathirana, R. y J.R. Eason; Establishment and characterization of a rapidly dividing diploid cell suspension culture of Arabidopsis thaliana suitable for cell cycle synchronization, Plant Cell Tiss. Org. Cult.: 85, 125-136 (2006).

Persson, S. y otros cinco autores; The $\mathrm{Ca}^{2+}$ status of the endoplasmatic reticulum is altered by induction of calreticulin expression in transgenic plants, Plant Physiol.: 126, 1092-1104 (2001).

Planchais, S., N. Glab, D. Inzé y C. Bergounioux, Chemical inhibitors: a tool for plant cell cycle studies, FEBS Lett.: 476, 78-83 (2000).

Reichheld, J.P. y otros cautro autores; Cell cycle-regulated histone gene expression in synchronized plant cells, Plant J.: 7, 245-252 (1995).

Renaudin, J.P.; Growth and physiology of suspension-cultured plant cells: the contribution of tobacco $B Y-2$ cells to the study of auxin action, In Tobacco BY-2 cells: Biotechnology in agriculture and forestry by T. Nagata, S. Hasezawa, y D. Inzé, vol. 53(347), pp 160-180. Springer-Verlag, Berlin y Heidelberg (2004).

Robledo-Paz, A., M.N. Vázquez-Sánchez, R.M. Adame-Álvarez y A.E. Jofre-Garfias, Callus and suspension culture induction, maintenance and characterization, In Plant Cell Culture Protocols: Methods in Molecular Biology by V.M. Loyola-Vargas y F. Vázquez-Flota, Second edition, vol. 318(393), pp 59-86, Humana Press Inc., USA (2006).

Samuels, A.L., J. Meehl, M. Lipe y L.A. Staehelin; Optimizing conditions for tobacco BY-2 cell cycle synchronization, Protopl.: 202, 232-236 (1998).

Sharma, A.K.; Synchronization in plant cells - an introduction, Meth. Cell Sci.: 21, 73-78 (1999).

Singh, N.K., A.K. Handa, P.M. Hasegawa y R.A. Bressan; Proteins associated with adaptation of cultured tobacco cells to NaCl, Plant Physiol.: 79, 126-137 (1985).

Singh, R.J.; Plant cytogenetics, Second edition, pp 277-326. CRC, USA (2002). 